\title{
Maximum likelihood estimation technique of grasscutter (Thryonomys swinderianus) production in Osun State, Nigeria
}

\author{
Olatidoye M. S. ${ }^{1 \star}$, Akinola A. A. ${ }^{1}$, Akinbode W. $0 .{ }^{1}$ and Owombo P. T. ${ }^{2}$ \\ ${ }^{1}$ Department of Agricultural Economics, Faculty of Agriculture, Obafemi Awolowo University, lle-Ife, Osun State, Nigeria. \\ ${ }^{2}$ Ondo State University of Science and Technology, Department of Agricultural Economics and Extension, Okitipupa, \\ Ondo State. \\ ${ }^{*}$ Corresponding author. Email: sharonsam2016@gmail.com
}

Copyright (C) 2019 Olatidoye et al. This article remains permanently open access under the terms of the Creative Commons Attribution License 4.0, which permits unrestricted use, distribution, and reproduction in any medium, provided the original work is properly cited.

Received 17th May, 2019; Accepted 7th June, 2019

\begin{abstract}
The study estimated quantitatively the technical efficiency of production and its determinants in grasscutter enterprise in Osun State, Nigeria, using a stochastic production frontier function approach. A total of Seventy-two grasscutter farmers across the three agricultural zones were selected using a simple random sampling technique. Data were collected on the socio-economic characteristics and other variables of interest such as prices of production inputs and output, through a well-structured questionnaire. The Maximum Likelihood Cobb-Douglas estimation procedure was used. Careful analysis revealed that labour, concentrates, capital and farm size were identified as the major determinants of the total output of grasscutter enterprise in the study area. The study also showed that membership of cooperative, access to credit, level of education and extension contact significantly influenced efficiency level in the study area. The maximum technical efficiency attained by the farmers was $93 \%$ while the minimum technical efficiency was found to be $45 \%$. The mean technical efficiency (MTE) was $86 \%$. The sum of output elasticities which denotes returns to scale was established at 1.04 signifying increased returns to scale. In essence, the enterprise did not attain maximum production frontier. Based on these findings, it is recommended that efficiency could be increased through better use of available resources, access to credit facilities and assisting and encouraging the farmers in joining cooperative societies so as to have access to loans. Also, educational programmes should be organized to sensitize farmers more on how to improve on their efficiency level.
\end{abstract}

Keywords: Assessment, grasscutter enterprise, efficiency, stochastic frontier.

\section{INTRODUCTION}

The efficiency of various livestock sub-sectors can be improved through efficient use of the existing technologies, reallocation of resources and adoption of new technologies (Adedeji et. al. 2013; Henry, 2014). The challenge to policy-makers is how to improve efficiency especially of the small farmers to attain large gains in agricultural output to help reduce food insecurity.

The deficiency of animal protein in the third world countries can be ameliorated by improving the efficiency of production and existing conservation programme of wildlife particularly the domestication of rodents that are tractable, prolific and widely acceptable to the public for consumption (Wogar et. al. 2017). Captive breeding of species as a possible way to satisfy local demand without compromising the wild stock has also been recommended (Adedeji et al. 2013; Akinola et al. 2015). Grasscutter or cane rat (Thryonomys swinderianus) has been suggested as one of the mini-livestock having the potential for domestication. Grasscutter rearing has been stated to have health-related benefits including better nutrition from consumption of meat (Adedapo and Adekunle, 2014).

Grasscutter is a hystricomorphic rodent widely distributed 
in the African sub-region and exploited in most areas as a source of animal protein. It is a heavily built animal with round muzzle, small round ears, short tail and harsh bristly fur. Apart from being the most preferred, it is the most expensive bush meat in most West African countries, Nigeria inclusive (Adedeji et al. 2013). It contributes to both local and foreign earnings in some of these countries. Most rural populations in Nigeria depend on bush meat for their dietary protein supply and most Chinese who are resident in Nigeria cherish grasscutter meat as regular meal and forms delicacy for entertainment for their guest from abroad (Henry, 2014). The preference for grasscutter is attributable to its high carcass quality and protein that is comparable to that of poultry, especially turkey and other domesticated livestock like rabbit, sheep, goat and cattle (Kusi et al., 2012). A crude protein content of $22.7 \%$ had been reported for Grasscutter meat. This value is higher than the crude protein values of $20.7 \%$ for rabbit meat, $19 \%$ for chicken meat, $18.2 \%$ for beef and $22.2 \%$ for turkey (Benjamin et al. 2016).

However, Onyeanusi and Famoyin (2005), opined that Nigeria as a developing country is faced with a worsening situation of inadequate protein consumption. The reason put forward is that out of the $54.5 \mathrm{~g}$ recommended per capita protein consumption per day, the protein supply was $44 \mathrm{~g}$ out of which animal products was less than $2.0 \%$. This has led to protein deficiency which is responsible for malnutrition that is widespread across all ages in Nigeria. This was further corroborated by Fakoya et al. (2008) who submitted that efficiency of production of farm animals in most developing nations is very low and cannot support the percapita requirements for animal proteins in those countries. Adedeji et al. (2013) pointed out that the current per capita animal protein consumption in Oyo and Osun States is less than $7.5 \mathrm{~g}$ and is similar in most States of the federation.

The situation remains so, partly because most farmers lack the technical knowledge, managerial ability and have failed to seek the counsels of experts which in turn limit their ability to maximize output that can translate into huge capital. This was further corroborated by the submissions of Akinola et al. (2015) and Olatidoye et al. (2018a), that one of the most serious constraints of agricultural growth in Nigeria is the inefficient use of productive resources and that considerable growth can be achieved by simply improving the level of efficiency in resource use.

Subsequently, small scale farmers dominate most of the Grasscutter farming enterprise and are regarded as part of the major contributors to livestock growth in the State. It is therefore imperative to lay emphasis on allocating and distributing adequate resource inputs, investments in research and eliminating the bottlenecks to efficient resource utilization at the farm level. Hence, the specific objectives of this study were to determine the technical efficiency of production of grasscutter's enterprise in the State, identify the factors influencing efficiency levels and make policy recommendations towards improving the sector in the study area and Nigeria at large.

\section{The Stochastic Frontier Model}

Following Farell (1957) article on efficiency measurement which led to the development of several approaches to efficiency and productivity analysis, among these is data envelopment analysis (DEA). As noted by Battese and Coelli (2008), the stochastic frontier is considered more appropriate than DEA in agricultural applications especially in developing countries where the data is likely to be influenced by measurement errors and the effects of weather conditions, diseases etc. This equally applies to the applications of frontier techniques to grasscutter production. However, the modelling and estimation of stochastic frontier production function has been a subject of considerable interest in econometrics and applied economic analysis during the last two decades. Review of frontier production are given by Bauer (1990) and Battese and Coelli (2008). The stochastic frontier production proposed by Battese and Coelli (2008) assumed that a random sample of farms is observed over $T$ period such that the production of the $\mathrm{N}$ farms over time is a given function of input variables and random variables which involve the traditional random error and non-negative random variables which are associated with technical inefficiencies of production. One of the earliest empirical studies in stochastic frontier production function was an analysis of the sources of technical inefficiency in the Indonesian Wheat industry by Pitt and Lee (1983).

The study estimated a stochastic frontier production function by the method of maximum likelihood and the prediction of technical inefficiencies were then regressed upon size of firm, age and ownership structure of each firm. These variables were found to have significant effect on the degree of technical inefficiency of the firms. Kareem et al. (2008) also investigated factors which influenced the technical inefficiency of fish farmers in Ogun State using a stochastic frontier production function which incorporated a model for the technical inefficiency effects. The results found out that some farmers were able to achieve maximum efficiency while others were technically inefficient. Akinola et al. (2015) and Olatidoye et al. (2018b) similarly investigated the determinants of cotton production and the economic efficiency of its production, respectively, using a stochastic frontier production function which incorporated a model of inefficiency effects. The results indicated that labour, capital investment and material inputs were the major factors associated with changes in the output of cotton. Farmer-specific variables which comprise, status of farmers, education, farming experience and access to credit facilities were found to be significant factors that accounted for the observed variation in inefficiency among cotton producers.

\section{Conceptual framework}

The frontier production model analysis for cross sectional 
data can be defined by considering a stochastic production function with a multiplicative disturbance terms of the forms:

$Y=f\left(X_{a} ; \beta\right) e^{\varepsilon}$

Where: $Y=$ the quantity of original output; $X_{a}=a$ vector of input quantities; $\beta=$ a vector of parameters and $\varepsilon=$ error term.

$\varepsilon=\mu+v$

Where: ' $\varepsilon$ ' is a stochastic disturbance term consisting of two independents elements ' $\mu$ ' and ' $v$ '.

The symmetric component ' $v$ ' accounts for random variation in output due to factors outside the farmer's control, such as weather and diseases. It is assumed to be independently and normally distributed with zero mean and constant variance as $\mathrm{N} \sim\left(0, \sigma^{2} v\right)$. A one-sided component $\mu<0$ reflects technical inefficiency relative to the stochastic frontier, $f\left(X_{a} ; \beta\right) e^{\varepsilon}$. Thus, $\mu=0$ for a farm output which lies on the frontier and $\mu<0$ for one whose output is below the frontier as $\left|\mathrm{N} \sim\left(0, \sigma^{2} \mathrm{u}\right)\right|$, that is, the distribution of ' $\mu$ ' is half normal.

The frontier of the farm is given by combining (1) and (2).

$Y=f(X a: \beta) e^{(u+v)}$

Measure of efficiency for each farm can be calculated as:

$\mathrm{TE}=\exp [E\{\mu / \varepsilon\}]$

And ' $\mu$ ' in equation (4) is defined as:

$\mu=f\left(Z_{b} \delta\right)$

Where: $Z_{b}=a$ vector of farmer specific factors and $\delta=a$ vector of parameters.

The parameters for the stochastic production frontier model in equation (3) and those for the technical inefficiency model in equation (5) were estimated simultaneously using the maximum likelihood estimation (MLE) programme, Frontier 4.1c, which gives the variance parameters of the likelihood function in terms of $\sigma^{2}=\sigma^{2} \mu+$ $\sigma^{2}{ }_{v}+y=\sigma^{2} \mu / \sigma^{2} v$. In terms of its value and significance, $y$ is an important parameter in determining the existence of a stochastic frontier: rejection of the null hypothesis, $\mathrm{Ho:} Y$ $=0$, implies the existence of a stochastic production frontier. Similarly, $y=1$ implies that all the deviations from the frontier are due entirely to technical inefficiency (Battese and Coelli 2008). However, in recent years, the Battese and Coelli model for the technical inefficiency has become more popular because of its computational simplicity as well as its ability to examine the effects on various firm-specific variables on technical efficiency in an econometrically consistent manner, as opposed to traditional two-step procedure. According to Kusi et al. (2012) technical inefficiency effects, $U_{\text {is }}$ in equation 1 are assumed to be independently distributed and truncations (at zero) of the normal distribution with mean $Z_{i} \delta$ and variance, $\sigma^{2} \mu\left|\mathrm{N}\left(Z_{i} \delta, S^{2} u\right)\right|$, where $Z_{i}$ is a $(1 \times m)$ vector of observable firm specific variables hypothesized to be associated with technical inefficiency, and $\delta$ is an ( $m \times 1)$ vector of unknown parameters to be estimated. Under these assumptions, the technical inefficiency effects, $U_{\text {is }}$ can be expressed as follows:

$U i=Z_{i} \delta+W_{i}$

Where; $\mathrm{W}_{\text {is }}$ are random variables, defined by the truncations of the normal distribution with mean zero and variance $\sigma^{2}$. . Such that the point of truncation is $-Z_{i} \delta$ i.e. $W i \geq Z i \delta$. If $Z$-variables also include interactions between firm-specific factors and input variables, then the Huang and Liu (1994) non-neutral stochastic frontier is obtained. The technical efficiency of the $i^{- \text {th }}$ sample of grasscutter farms is denoted by:

$T E=\exp (-U)=\exp (-Z ; \delta-W)$.

\section{MATERIALS AND METHODS}

\section{The study area, sampling technique and data collection}

The study was carried out in Osun State comprising thirty Local Government Areas. The State Agricultural Development Programme (ADP) classified the State into three agricultural zones based on the variations in vegetation cover. These are: Iwo, Osogbo and Ife-ljesa zones (Figure. 1). The State is located in the South-West geopolitical zone of Nigeria and occupies an area of land of about 14, $875 \mathrm{~km}^{2}$. The ecological conditions are conducive for an impressive diversity of livestock such as cattle, sheep, goat, pig, rabbit, grasscutter and poultry. The State has a population of about 3.5 million (NPC, 2006) and the vegetation is characteristically that of the rain forest and derived savannah with a mean annual rainfall that varies between 980 and $2800 \mathrm{~mm}$ and a temperature range of 27 to $32^{\circ} \mathrm{C}$.

Primary data were collected through structured questionnaire administered at the three agricultural zones of the State. The Resident Agricultural Extension Agents and Osun State Agricultural Development Programme (OSSADEP), were the sources of the list of the registered grasscutter farmers, which formed the sampling frame for the study. From the list provided, 30 grasscutter farmers were registered in Iwo zone, 35 in Osogbo and 39 in IfeIJesa zone. A simple random sampling technique was employed to select Twenty-four Grasscutter farmers from 


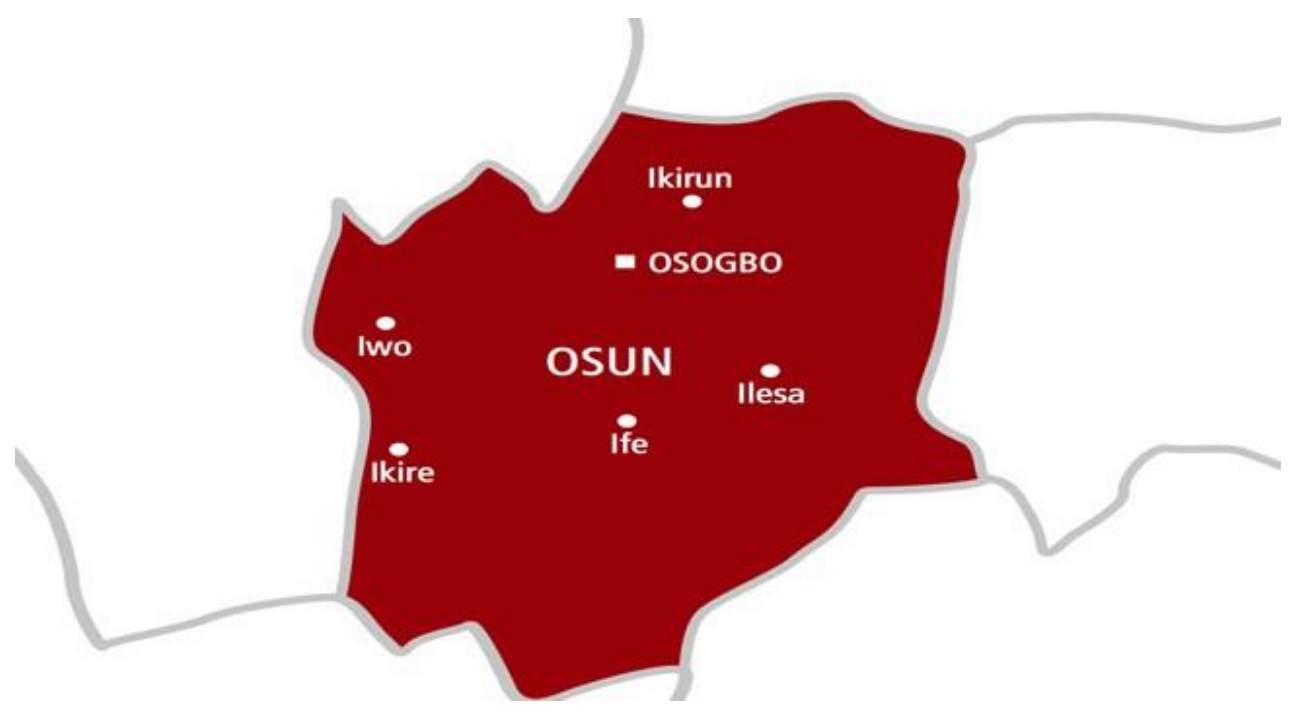

Figure 1. Map of Osun State, Nigeria showing the three Agricultural zones (Iwo and Ikire $\equiv$ Iwo zone; Ikirun and Osogbo $\equiv$ Osogbo zone; Ife and llesa I Ife-ljesa zone).

each of the agricultural zones to make a total sample size of 72 respondents. Data collected include socioeconomic characteristics of farmers and production activities in terms of inputs, outputs and their respective prices for the year 2018.

\section{Analytical technique}

The stochastic production frontier approach was used in estimating technical efficiency scores of grasscutter production as well as the factors influencing efficiency levels as it provides better results, allows for the measurement of random errors such as inefficiencies of production, statistical noise measurement and the confidence of the results is much higher than from nonparametric models (Ajao et al. 2012). The frontier production function was specified by the Cobb-Douglas production function including all the explanatory variables. Following Ajao et al. (2012), one-step procedure was employed given away the biases of the two steps potential estimation procedure. It is worth stating that this functional form has been widely used in farm efficiency analysis for both developing and developed countries with great success (Olukole et al., 2010; Ajao et al., 2012). Furthermore, in one of the few studies that examined the impact of functional form on efficiency, Adedapo and Adekunle (2014) submitted that functional specification has a discernable but rather small impact on estimating efficiency. Thus, the model's basic structure is as specified below:

$Y_{i}=f(X, \beta) \mathrm{e}^{v-u}$

However, the empirical model for technical efficiency in grasscutter enterprises is stated thus: $\ln Y_{i j}=\beta_{0}+\beta_{1} \ln X_{1 i j}+\beta_{2} \ln X_{2 i j}+\beta_{3} \ln X_{3 i j}+\beta_{4} \ln X_{4 i j}+\beta_{5} \ln$ $X_{5 i j}+\beta_{6} \ln X_{6 i j}+\left(v_{i}-u_{i}\right)$

Where: $L n=$ Logarithm to base e $\beta_{0}, \beta_{1}-\beta_{6}$ are parameters to be estimated; $Y=$ Output or total value of grasscutter products $(\# / K g) ; X_{1}=$ Concentrates $(\#) ; X_{2}=$ Green feeds $\left(\mathrm{Kg} /\right.$ Colony); $X_{3}=$ Drugs and Medication ( $) ; X_{4}=$ Capital inputs (\#); $X_{5}=$ Labour (Mandays); $X_{6}=$ Farm size (Number of grasscutter housed on the farm); $V_{i}=$ Normal random errors which are assumed to be independent and identically distributed having $\mathrm{N}\left(0 \delta \mathrm{v}^{2}\right)$. They are not under the control of the farmer e.g. weather, diseases and measurement error; and $U_{i}=$ Non-negative random variables assumed to account for technical inefficiency in the production function and are assumed to be $\mathrm{N}\left(0 \delta \mathrm{v}^{2}\right)$.

\section{RESULTS AND DISCUSSION}

The maximum likelihood estimates (MLE) of the stochastic frontier production function are represented in Table 1. The estimate of sigma-squared $\left(\sigma^{2}\right)$, which is 0.231 is significantly different from zero, indicating a good fit and correctness of distributional assumption specified. The variance of ratio $(\mathrm{Y})$ which measures the effect of technical inefficiency in the variations of observed output has a value of 0.19 . This implies that about $19 \%$ of the difference between the observed and maximum production frontier outputs were due to differences in farmer's level of technical efficiency and not related to random variability. Hence, those factors are under the control of the farm and the influence of which can be reduced to enhance the technical efficiency of the grasscutter production. The firmspecific technical efficiency also varied between 0.45 and 1 (Table 2) with mean technical efficiency (TE) of 0.86 . This implies that in the short-run, it is possible to increase 
Table 1. Maximum likelihood estimates of the parameters of the stochastic production function (Technical Efficiency Model).

\begin{tabular}{|c|c|c|c|c|}
\hline Production factors & Parameters & Estimated coefficients & Standard errors & t-values \\
\hline Constant term & $\beta_{0}$ & 3.101 & 0.319 & 9.721 \\
\hline Concentrates $\left(\mathrm{X}_{1}\right)$ & $\beta_{1}$ & 0.229 & 0.054 & $4.241^{*}$ \\
\hline Green feeds $\left(X_{2}\right)$ & $\beta_{2}$ & 0.127 & 0.115 & 1.095 \\
\hline Drugs and medication $\left(\mathrm{X}_{3}\right)$ & $\beta_{3}$ & 0.135 & 0.109 & 1.238 \\
\hline Capital inputs $\left(\mathrm{X}_{4}\right)$ & $\beta_{4}$ & 0.329 & 0.131 & $2.511^{* *}$ \\
\hline Labour $\left(X_{5}\right)$ & $\beta_{5}$ & -0.079 & 0.038 & $-2.099^{* *}$ \\
\hline Farm size $\left(X_{6}\right)$ & $\beta_{6}$ & 0.294 & 0.112 & $2.625^{*}$ \\
\hline \multicolumn{5}{|l|}{ Inefficiency factors } \\
\hline Constant $\left(Z_{0}\right)$ & $\delta_{0}$ & 0.092 & 0.017 & 5.142 \\
\hline Age $\left(Z_{1}\right)$ & $\delta_{1}$ & 0.127 & 0.095 & 1.337 \\
\hline Access to $\operatorname{credit}\left(Z_{2}\right)$ & $\delta_{2}$ & -0.092 & 0.042 & $-2.215^{\star *}$ \\
\hline Farming experience $\left(Z_{3}\right)$ & $\delta_{3}$ & -0.319 & 0.057 & $-6.380^{*}$ \\
\hline Level of education $\left(Z_{4}\right)$ & $\delta_{4}$ & -0.118 & 0.034 & $-3.471^{*}$ \\
\hline Membership of cooperative $\left(Z_{5}\right)$ & $\delta_{5}$ & -0.113 & 0.057 & $-1.983^{\star \star}$ \\
\hline Extension contact $\left(Z_{6}\right)$ & $\delta_{6}$ & -0.037 & 0.014 & $-2.643^{\star *}$ \\
\hline Gender $\left(Z_{7}\right)$ & $\delta_{7}$ & 0.055 & 0.037 & 1.486 \\
\hline Household size $\left(Z_{8}\right)$ & $\delta_{8}$ & 0.597 & 0.681 & 0.877 \\
\hline \multicolumn{5}{|l|}{ Diagnostic statistics } \\
\hline Sigma-squared & $\sigma^{2}$ & 0.231 & 0.073 & \\
\hline Gamma (Y) & & 0.193 & 0.101 & \\
\hline LR test & & 17.13 & & \\
\hline Log-likelihood function & & 21.15 & & \\
\hline
\end{tabular}

Source. Survey data, 2018. ${ }^{*}=1 \%$ and ${ }^{* *}=5 \%$ alpha level.

Table 2. Frequency distribution of technical efficiency of grasscutter farmers.

\begin{tabular}{lcc}
\hline Efficiency level & Frequency & Percentage \\
\hline $0.41 \leq \mathrm{Te}<0.50$ & 9 & 12.5 \\
$0.51 \leq \mathrm{Te}<0.60$ & 13 & 18.1 \\
$0.61 \leq \mathrm{Te}<0.70$ & 8 & 11.1 \\
$0.70 \leq \mathrm{Te}<0.80$ & 17 & 23.6 \\
$0.80 \leq \mathrm{Te}<0.90$ & 21 & 29.2 \\
$\mathrm{Te} \geq 0.9$ & 4 & 5.56 \\
Total & 72 & 100 \\
Maximum $\mathrm{Te}=0.93$ & & \\
Minimum $\mathrm{Te}=0.45$ & & \\
Mean $\mathrm{Te}=0.86$ & & \\
\hline
\end{tabular}

output in the study area on the average by $14 \%$ by using the technology of the best performer.

The constant term for grasscutter enterprise (Table 1) is positive and statistically significant. It shows the level of output or revenue accruable to the farmer at zero level of use for each of the inputs. The estimated coefficient is 3.101. In essence, the farmer could rent out some fixed cost items owned by the enterprise which could as well account for the positive constant terms. An estimate of Cobb-Douglass production function for grasscutter production in the study area presented in Table 1 shows that all the explanatory variables (except labour) included in the model for grasscutter farms had expected signs. However, concentrates, capital inputs, labour and farm size, among other variables, were found to be statistically significant. The quantity of grasscutter concentrates/ pelletized feeds available influenced grasscutter yield/ output positively and significant at $1 \%$ probability level such that a $100 \%$ increase in the quantity of the concentrates increases grasscutter output by $18.9 \%$. This suggests increase in the concentrates a farmer use, results in higher output. This finding concurs with Kusi et al. (2012) which indicated that productivity of intensive smallholder livestock production systems directly correlates with the amount of pelletized feeds and feeding available to the animal. The capital inputs for the enterprise showed a positive coefficient as hypothesized which was significant at $1 \%$ level. Thus, up to $100 \%$ increase in the amount of capital available to grasscutter enterprise significantly improved productivity by $32.9 \%$. The results also revealed that capital input and availability was the factor with the highest impact on the productivity of the grasscutter enterprise. The findings are consistent with 
Wogar et al. (2017) in which investment capital was found to be a key factor in the Grasscutter's production. Capital as a factor of production enhances farm infrastructure and small holder grasscutter rearing farm structures construction, purchase of modern grasscutter rearing equipment, and technology transfer, and hence its great effect on productivity.

The estimated coefficient of labour was negative and statistically significant at the $5 \%$ probability level. This implies that when labour increases from the present levels, grasscutter production declines. The plausible explanation for this observation is that, increase in the size of labour enables the farmer to shift away from grasscutter farming to other alternative activities which could be more profitable. Additionally, it could be because of poor or lack of information, ignorance or limited knowledge on the part of the farmers on about the right proportions of this critical input application and use; hence they might have overapplied or under-applied labour, leading to negative effects on output. This agrees with the findings of Olukole et al. (2010) and Kusi et al. (2012).

The estimated coefficient of farm size is positively signed and statistically significant at $1 \%$ probability level. This conforms to a-priori expectations. The scale of production in a given farm enterprise affect the output and hence profitability of the farms (Akinola et al. 2015). Fakoya et al. (2008) stressed that the more farm animals are housed together, the better economic gains the operation yields. Benjamin et al. (2016) also stressed that the net income increases in direct proportion to the size of the flock. The elasticity of farm size is 0.294 , which implies that $100 \%$ increase in grasscutter colonies (farm size) would lead to a $29.4 \%$ increase in the output or revenue accruing to the enterprise. The return to scale (sum of production elasticities) was 1.04 (Table 3). Since this is greater than unity thus indicating an increasing return to scale. Hence, the farmers can be said to be operating in stage 1 of production and there is a need for improvement such as optimizing more variable inputs to boost production.

The farm specific efficiency distribution is shown in Table 1. For policy purposes, it is useful to identify the sources of these inefficiencies which can be done by investigating the relationship between the computed TE and $\delta_{1}-\delta_{6}$. All the variables have a negative relationship with TE except $\delta_{1}, \delta_{7}$ and $\delta_{8}$. The variables with positive coefficients were age, gender and household size and incidentally not significant at either 1 or $5 \%$ probability levels. It should be noted that a negative coefficient means that the variable is improving technical efficiency; that is the farmer becomes less technically inefficient as the level of the variable increases. A positive coefficient, on the other hand, implies technical inefficiency. However, the results showed that access to credit, membership of cooperative society and extension contact were negatively signed and significant at $5 \%$ probability levels. While Farming experience and level of education were also negatively signed and significant at $1 \%$ level. In essence, the estimated coefficient for access to credit and membership of cooperative
Table 3. Distribution of production elasticity among variables for grasscutter enterprise.

\begin{tabular}{lc}
\hline Variables & Estimated values \\
\hline Concentrates & 0.229 \\
Green feeds & 0.127 \\
Drugs and medication & 0.135 \\
Capital inputs & 0.329 \\
Labour & -0.079 \\
Farm size & 0.294 \\
Sum of elasticities & 1.035 \\
\hline
\end{tabular}

Source: Survey data, 2018.

society were both negatively signed and statistically significant at $5 \%$ level, which conforms to a-priori expectations.

The number of associations a farmer belongs to is expected to influence his interactions positively with his fellow farmers and enhances the possibility of accessing agricultural credit. Hence, farmers in these categories tend to be less technically inefficient. These findings agree with Owen and Dike, (2013) and Benjamin et al. (2016). Hence, access to credit, farming experience, level of education, membership of cooperative society and extension contact were the factors that influenced the level of efficiency of grasscutter farmers and producers in the study area. The results further showed that $29 \%$ of the sampled farmers have technical efficiencies ranging between 0.81 and 0.90 . The technical efficiency estimates are widely distributed across the respective grasscutter farmers (Table 2). The minimum technical efficiency value was $45 \%$ indicating that some farmers are located far from the frontier region while the maximum technical efficiency was $93 \%$ indicating that some farmers are very close to the frontier region. The mean technical efficiency value of $86 \%$, however, portrays that there is a wide opportunity for the grasscutter farmers to increase their current level of technical efficiency. The analysis however implies that it will take an average grasscutter farmer $(1-0.86 / 0.93)$ which equals $7.5 \%$ cost saving to become the most efficient grasscutter farmer on the sampled ten group while the worst performing grasscutter farmers $(1-0.45 / 0.93)$ would need $52 \%$ cost saving to become the most efficient grasscutter farmer in the worst 10 sampled group.

\section{Conclusion and recommendation}

This study empirically estimated technical efficiency of grasscutter farms and identified the socio-economic factors that determine the level of estimated technical efficiency of the sampled respondents. The study found the average technical efficiency estimate to be $86 \%$ and returns to scale of 1.04 . It therefore concluded that $14 \%$ of the farmers' output or income is lost to technical inefficiency as influenced by access to credit, farming 
experience, level of education, membership of cooperative society and extension contact. The direct variable inputs which can increase grasscutter output are concentrate, capital input, labour and farm size. This implies that the combined effects of the above stated direct variables can bring a substantial increase in Grasscutter output. Additionally, consistent availability of these inputs can ensure commensurate grasscutter's products and generates additional income for the farmers. It is therefore recommended that financial institutions and NGOs targeting at grasscutter's farmers should improve the farmers' access to credit. In addition, new entries and existing farmers of grasscutter need to undergo formal training and educational programmes such as workshop and seminars to improve technical efficiency.

\section{CONFLICT OF INTEREST}

The authors declare no conflict of interest.

\section{REFERENCES}

Adedapo, A. A., \& Adekunle, A. O. (2014). Economic aspects of grasscutter farming in southwest Nigeria: Implications for sustainable adoption and conservation. International Journal of Scientific and Engineering Research, 4(10), 17-23.

Adedeji, I. A., Adelalu, K. O., Ogunjimi, S. I., \& Otekunrin, A. O. (2013). Application of stochastic production frontier in estimation of technical efficiency of poultry egg production in Ogbomoso metropolis of Oyo State, Nigeria. World Journal of Agricultural Research, 1(6), 119-123.

Ajao, A. O., Ogunniyi, L. T., \& Adepoju, A. A. (2012). Economic Efficiency of soybean production in Ogo-Oluwa Local Government Area of Oyo State, Nigeria. American Journal of Experimental Agriculture, 2(4), 667-679.

Akinola, L. A. F., Etela, I., \& Emiero, S. R. (2015). Grasscutter (Thryonomys swinderianus) production in West Africa: Prospects, challenges and role in disease transmission. American Journal of Experimental Agriculture, 6(4), 196-207.

Battese, G. E., \& Coelli, T. J. (2008). Prediction of Firm-level Technical Efficiencies with a Generalized Frontier Production function and Panel data.

Bauer, P.W. (2013). Recent Developments in the Economic Estimation of Frontiers. Journal of Econometrics, 46(2), 39-56.

Benjamin, U. U., Akinyemi A. F., \& ljeomah H. M. (2016). Problems and prospects of grasscutter (Thryonomys swinderianus) farming in Ibadan, Nigeria. Journal of Agriculture, Forestry and Social Sciences, 4(2), 24-32.

Fakoya, E. O., Sodiya, C. I., Alarima, C. I., \& Omoare, A. M. (2008). Information needs of farmers in grasscutter production for improving performance in Ona-Ara Local Government Area of Oyo State. Proceedings of 33rd Annual Conference of Nigerian Society for Production. Ayetoro, Ogun State, Nigeria. Pp. 300-301.
Farrell, M. J. (1957). The measurement of productive efficiency. Journal of the Royal Statistical Society: Series A, 120(4), 253281.

Henry, A. J. (2014). Reproductive performance of grasscutter does at first parity reared in humid tropical environment. Proceedings of 38th Annual Conference of Nigeria. Society for Animal Production, University of Ibadan, Nigeria. Pp. 155-158.

Kareem, R. O., Dipeolu, A. O., Aromolaran, A. B., \& AkegbejoSamson (2008). Analysis of technical, allocative and economic efficiency of different pond systems in Ogun State, Nigeria. African Journal of Agricultural Research, 3(4), 246-254.

Kusi, C., Tuah, A. K., Annor, S. Y., \& Djang-Fordjour, K. T. (2012). Determination of dietary crude protein level required for optimum growth of the grasscutter in captivity. Livestock Research for Rural Development, 24(10). Available at https://lrrd.cipav.org.co/lrrd24/10/kusi24176.htm.

NPC (2006). National Population and Housing Census Report, 2006.

Olatidoye, M. S., Alimi, T. and Akinola, A. A. (2018a). Determinants of technical efficiency in cotton production in the southern cotton growing zone of Nigeria: A stochastic production frontier approach. Asian Journal of Agriculture, 2(2), 58-64.

Olatidoye, M. S., Kehinde, A. D. \& Alimi, T. (2018b). Forecasting the future farm size in grasscutter production in Osun State, Nigeria: A Markov Chain Approach. Asian Journal of Research in Agriculture and Forestry, 2(3), 1-10.

Olukole, S. G., Oyeyemi M. O., \& Oke, B. O. (2010). Gross anatomy of male reproductive organs of the domesticated grasscutter (Thryonomys swinderianus Temmink). Proceedings of 25th Annual Conference of Nigerian Society for Animal Production. University of Ibadan, Nigeria. Pp. 268-271.

Onyeanusi, A. E., \& Famoyin, J. B. (2005). Health care management of grasscutter in captivity: Assessment of causes of mortalities among rearing stock in Ibadan metropolis. Journal of Forestry Research and Management, 2(5), 58-66.

Owen, O. J., \& Dike, U. A. (2013). Japanese quail (Coturnixcoturnix japonica) husbandry: A means of increasing animal protein base in developing countries. Journal of Environmental Issues and Agriculture in Developing Countries, 5(1), $1-4$.

Pitt, M. M., \& Lee, L. F. (1983). The measurement and sources of technical inefficiency in the Indonesian weaving industry. Journal of DevelopmentEconomics,9(2), 43-46.

Wogar, G. S. I., Effiong, O. O., \& Nsa, E. E. (2017). Performance of growing grasscutter on different fibre sources. Pakistan Journal of Nutrition, 11(1), 51- 53. 